\title{
Stimulant use among prehospital emergency care personnel in Gauteng Province, South Africa
}

\author{
L-R van Rooyen, BTech EMC; R Gihwala, MB ChB, MMed (Emerg Med), FCEM; \\ A E Laher, MB BCh, MMed (Emerg Med), FCEM, Cert Critical Care (SA), EDIC, Dip PEC (SA), DCH, Dip Allerg (SA), Dip HIV Man (SA)
}

Department of Emergency Medicine, Faculty of Health Sciences, University of the Witwatersrand, Johannesburg, South Africa

Corresponding author: A E Laher(abdullahlaher@msn.com)

Background. Emergency medical service (EMS) personnel are exposed to high levels of psychological, physical and emotional stressors. There has been an increase in stimulant use among healthcare professionals worldwide. There is a paucity of data pertaining to the use of stimulant products among EMS personnel in South Africa (SA).

Objectives. To determine the prevalence of and other aspects pertaining to use of stimulant products among EMS personnel in Gauteng Province, SA.

Methods. A prospective cross-sectional study using a questionnaire-based model was used to survey EMS personnel in Gauteng.

Results. Of the 315 respondents who completed the questionnaire, 310 (98.4\%) reported use of stimulant products, 295 (93.7\%) consumed tea/coffee, 187 (59.4\%) consumed commercial energy drinks, 60 (19.0\%) used caffeinated energy-enhancing tablets, 14 (4.4\%) used noncaffeinated prescription stimulant medications, 50 (15.9\%) used illicit drugs, $134(42.5 \%)$ exceeded the recommended daily allowance (RDA) of caffeine, 201 (63.8\%) exceeded the RDA of sugar, 231 (73.3\%) experienced difficulty remaining awake during a shift, $148(47.8 \%)$ used stimulants off shift, and $71(22.5 \%)$ experienced insomnia. Common reasons for use of stimulants were enjoyment $(n=218 ; 69.2 \%)$, to stay awake $(n=125 ; 39.7 \%)$ and improvement of physical and mental performance ( $n=94 ; 29.8 \%)$.

Conclusions. The high prevalence of stimulant use among respondents is a cause for concern. Strategies to address it should be aimed at promoting awareness and education, improving working conditions, enhancing support structures, and regulating the stimulant content of commercial products.

S Afr Med J 2021;111(6):587-590. https://doi.org/10.7196/SAMJ.2021.v111i6.15465

Stimulants such as caffeine, nicotine, methylphenidate, cocaine and methamphetamines are a class of drugs that have the ability to stimulate the central nervous system and thereby enhance cognitive and/or physical functionality. ${ }^{[1-3]}$ Owing to their dominant psychotropic properties, which include mood enhancement, increased perception and cognition, these substances have also been described as 'psychostimulants. ${ }^{[3]}$

It is estimated that $\sim 85 \%$ of adults in the USA consume caffeine daily, with coffee being the most commonly consumed caffeinated beverage. ${ }^{[2]}$ In 2006, a global increase in energy drink sales and consumption was noted, with $\sim 500$ new energy drinks being released into the market. ${ }^{[1]}$ The consumption of coffee and energy drinks in SA is on the increase as the country adapts to growing trends worldwide. ${ }^{[4]}$

The estimated amount of caffeine per serving in commonly consumed products varies considerably, with energy drinks (71 $422 \mathrm{mg}$ ) and over-the-counter stimulant medications (32 - $200 \mathrm{mg}$ ) having the highest content, followed by coffee $(40-108 \mathrm{mg})$, sodas $(25-55 \mathrm{mg})$ and tea $(9-50 \mathrm{mg})$. Caffeine consumed in doses between 85 and $200 \mathrm{mg}$ may decrease fatigue and increase alertness; however, the downside of caffeine consumption to combat fatigue is that once arousal from caffeine's effect becomes too high, performance decreases significantly. ${ }^{[2]}$ Excessive use of caffeine, exceeding $200 \mathrm{mg}$ per serving or $400 \mathrm{mg}$ per day, may result in caffeine toxicity, which manifests with tremors, insomnia, seizures, hypokalaemia and other effects resulting from hyperstimulation of the cardiovascular, gastrointestinal and central nervous systems. ${ }^{[1,5,6]}$ Other studies have also linked the consumption of energy products to changes in blood pressure, sudden cardiac death, elevated creatinine, an increase in platelet aggregation, and endothelial dysfunction. ${ }^{[6-8]}$

In addition to caffeine, energy drinks and other stimulantcontaining products contain large amounts of sugar, ${ }^{[5,6]}$ with some energy drink brands containing as much as 20 teaspoons of sugar per $500 \mathrm{~mL} .{ }^{[4]}$ This high sugar content far exceeds the World Health Organization's recommended daily allowance (RDA) of 6 12 teaspoons of sugar per day for adults. ${ }^{[9]}$ These high quantities of sugar increase the risk of developing lifestyle-related diseases such as diabetes mellitus, renal insufficiency, obesity and dental decay. ${ }^{[5,10]}$ Some products also contain a cocktail of other physical and mental enhancers such as guarana, taurine, ginseng and other herbs, which may also potentiate the adverse health effects of excessive caffeine consumption. ${ }^{[11]}$

Prolonged and excessive use of stimulants may pose a health risk, and impact negatively on patient management and care. ${ }^{[12]}$ There has been an increase in stimulant and illicit drug use in the medical fraternity. ${ }^{[13]}$ The use of caffeine and other stimulant products by healthcare professionals to combat fatigue and maintain physical and cognitive function while on duty has been well documented. ${ }^{[2,14]}$ In addition, the use of prescription stimulant medications such as methylphenidate, pemoline and modafinil, which mimic the effects of caffeine, is on the increase among medical practitioners and medical students. ${ }^{[12,15]}$ Stimulant use among emergency medical service (EMS) personnel, the military and other shift workers has been shown to be much higher than in the general population. ${ }^{[10]}$ In $\mathrm{SA}$, there is no legislation pertaining to the maximum amount 
of caffeine that is allowed in stimulant energy drinks, only that the products must have a warning when the amount is over $150 \mathrm{mg} / \mathrm{L} .{ }^{[4]}$

EMS personnel are regularly faced with high levels of psychological, physical and emotional stressors in their work and personal lives. ${ }^{[16]}$ Ongoing exposure to these stressors may exacerbate health ailments, predispose to substance abuse and impair work performance, thereby affecting patient care..$^{[17,18]}$

\section{Objectives}

There is a paucity of data pertaining to the use of stimulant products among EMS personnel in SA. We hypothesised that there is a high prevalence of stimulant use in this group. Our objective was therefore to determine the prevalence of and other aspects pertaining to the use of stimulant products among EMS personnel in Gauteng Province, SA.

\section{Methods}

This was a prospective, questionnaire-based cross-sectional study conducted between 1 May and 16 October 2019. The study population comprised EMS personnel employed at one of seven EMS providers in two metropolitan municipalities in Gauteng. Permission to conduct the study was obtained from each of the service providers, while ethics clearance was obtained from the University of Witwatersrand Human Research Ethics Committee (ref. no. M181116).

Data were collected by the primary investigator (L-RvR), who attended continuing medical education events as well as approaching potential participants at the various operation bases. To ensure that all shifts were adequately represented, data collection was conducted during both day and night shifts. Potential participants were first given a study information sheet that outlined the study objectives, and thereafter a quick response link to the online questionnaire. Study consent was automatically assumed when participants chose to complete the survey.

The questionnaire included questions pertaining to gender, experience, qualifications, difficulty staying awake during a shift, insomnia, and aspects pertaining to stimulant consumption, including the quantity of various stimulant products consumed, use of illicit drugs, reasons for stimulant consumption and increasing frequency of stimulant consumption. Data pertaining to the quantity of stimulant consumption were used to calculate the percentage of the RDA for caffeine and sugar.

Data were electronically captured into a data collection sheet that was created in the RedCap system. ${ }^{[19]}$ Captured data were thereafter exported to Excel (Microsoft 365, USA) for further analysis. Relevant data were tabulated and described using frequencies and percentages.

\section{Results}

Of the total of 501 EMS personnel who were approached, 315 completed the questionnaire, giving a response rate of $62.9 \%$. Table 1 describes the characteristics of the study participants, including perceptions relating to stimulant use. Of note, most participants were male ( $n=226 ; 71.1 \%)$, had $>10$ years of EMS experience $(n=125$; $39.7 \%)$ and had an advanced-level qualification $(n=133 ; 42.2 \%)$.

\begin{tabular}{|c|c|}
\hline Characteristics & $n(\%)$ \\
\hline Male & $226(71.7)$ \\
\hline \multicolumn{2}{|l|}{ Experience (years) } \\
\hline$\leq 5$ & $104(33.0)$ \\
\hline $6-10$ & $86(27.3)$ \\
\hline$>10$ & $125(39.7)$ \\
\hline \multicolumn{2}{|l|}{ Qualifications } \\
\hline Basic-level qualification & $76(24.1)$ \\
\hline Intermediate-level qualification & $106(33.7)$ \\
\hline Advanced-level qualification* & $133(42.2)$ \\
\hline Consumption of stimulant-containing products & $310(98.4)$ \\
\hline Caffeinated beverages (tea/coffee) & $295(93.7)$ \\
\hline Caffeinated commercial energy drinks ${ }^{\dagger}$ & $187(59.4)$ \\
\hline Caffeinated-energy enhancing tablets ${ }^{\ddagger}$ & $60(19.0)$ \\
\hline Non-caffeinated prescription stimulant medication ${ }^{\varsigma}$ & $14(4.4)$ \\
\hline Use of illicit drugss & $50(15.9)$ \\
\hline Exceeded RDA of caffeine & $134(42.5)$ \\
\hline Exceeded RDA of sugar & $201(63.8)$ \\
\hline Difficulty staying awake during shift & $231(73.3)$ \\
\hline Use of stimulants off shift & $148(47.8)$ \\
\hline Experiences insomnia & $71(22.5)$ \\
\hline Perceives that insomnia is secondary to stimulant use & $33(10.5)$ \\
\hline Perceives that stimulant use among EMS personnel is a problem & $252(80.0)$ \\
\hline Unaware that some regularly consumed products contain stimulants & $87(27.6)$ \\
\hline Required hospital admission due to excessive stimulant use & $5(1.6)$ \\
\hline Experiences withdrawal symptoms if adequate amount of stimulant not consumed & $97(30.8)$ \\
\hline Perceived increased risk of health complications from excessive stimulant use & $298(94.6)$ \\
\hline \multicolumn{2}{|c|}{$\begin{array}{l}\text { RDA = recommended daily allowance. } \\
{ }^{*} \text { Emergency Care Technician, Critital Care Assistant, Advanced Life Support, Dip EMC, National Diploma in Emergency Medical Care, Emergency Care Practitioner } \\
\text { "Monster, Red Bull, Rockstar, Dragon, Mofire, Wicked, Switch, Play. } \\
\text { tRegmakers, Bioplus, Statay Awake, Maccabs, Berocca, Rapid Energy. } \\
\text { 'Methylphenidate (Ritalin, Concerta), modafinil. }\end{array}$} \\
\hline
\end{tabular}


More than half the participants $(n=187 ; 59.4 \%)$ reported consumption of caffeinated commercial energy drinks, while approximately one-fifth $(n=60 ; 19.0 \%)$ reported consumption of caffeinated energyenhancing tablets. Monster was the most commonly consumed caffeinated commercial energy drink $(n=111 ; 35.2 \%)$. Among the 50 participants (15.9\%) who reported use of illicit substances, marijuana was most commonly used $(n=43 ; 13.7 \%)$. The RDA of caffeine and sugar was exceeded by $134(42.5 \%)$ and $210(63.8 \%)$ participants, respectively.

Almost three-quarters of the participants $(n=231 ; 73.3 \%)$ reported experiencing difficulty in remaining awake during their shifts, while $252(80.0 \%)$ perceived that stimulant use among EMS personnel was a problem and $87(27.6 \%)$ were unaware that regularly consumed products contained stimulants.

Almost a third of the participants $(n=97 ; 30.8 \%)$ reported experiencing withdrawal symptoms if adequate amounts of stimulant were not consumed. Overall, most subjects ( $n=298$; 94.6\%) perceived that excessive stimulant intake increases the risk of developing health complications.

Table 2 describes the reasons for stimulant consumption as well as reasons for the increasing frequency of stimulant consumption over time. Enjoyment $(n=218 ; 69.2 \%)$ and to stay awake or alert $(n=125$; $39.7 \%$ ) were the most common reported reasons for stimulant consumption. Among the 111 participants (35.2\%) who reported an increase in the frequency of stimulant consumption over time, to combat stress $(n=85 ; 76.6 \%)$ and to cope with an increase in the intensity of work $(n=54 ; 48.6 \%)$ were given as the most common reasons.

\section{Discussion}

Although studies have reported on caffeine and other stimulant use among healthcare workers in general, ${ }^{[20-22]}$ there is a paucity of data pertaining to stimulant use among EMS personnel. ${ }^{[10,23]}$ Like other healthcare professionals, ${ }^{[24-26]}$ EMS personnel are susceptible to stimulant and drug use as a result of exposure to various work-related stressors. ${ }^{[27,28]}$

Although previous studies have not specifically quantified stimulant and sugar consumption among EMS workers, consumption in the present study was excessive, with the RDA for caffeine ( $400 \mathrm{mg}$ per day $)^{[29]}$ and sugar (6 - 12 teaspoons per day ${ }^{[4,9]}$ being exceeded by $42.5 \%$ and $63.8 \%$ of study participants, respectively. The high rates of consumption of these products among study respondents are of concern and call for strategies to increase awareness, improve working conditions and limit use of stimulant- and sugar-containing products.

In a study that investigated predictors of stimulant use among 107 physicians in Nigeria, ${ }^{[24]} 92.5 \%$ of respondents were male, $27.1 \%$ had $>10$ years of experience, $89 \%$ reported use of stimulants, $26 \%$ used stimulants at home, $83 \%$ consumed coffee, $35.1 \%$ consumed caffeinated energy drinks, and $54.5 \%$ consumed kola nut (an edible caffeine-containing nut that is native to tropical rainforests in Africa). Among the reasons given, 55\% used stimulants to keep alert, $50 \%$ to stay awake, $42 \%$ for pleasure and $37 \%$ to cope with stress. ${ }^{[24]}$ Similarly, in a survey that investigated the use of neurocognitive enhancement substances among 716 EMS personnel in San Diego, USA, 86\% of respondents were male, $69 \%$ reported daily use, $63 \%$ consumed marketed energy drinks, $31 \%$ consumed tea or coffee, $8 \%$ used prescription psychostimulant medications, and $72 \%$ used several products in combination. Additionally, $52 \%$ of respondents reported the presence of sideeffects, while $3 \%$ had required medical attention secondary to use of these substances. The most cited reasons for use were to stay awake and to increase energy for recreational activities, while $61 \%$ believed that their job performance benefited. ${ }^{[30]}$ In comparison, in the present study, $71.7 \%$ of respondents were male, $39.7 \%$ had $>10$ years of experience, $98.4 \%$ used stimulant-containing products, $47.8 \%$ used stimulants off shift, $93.7 \%$ consumed tea or coffee, $59.4 \%$ consumed caffeinated commercial energy drinks, $4.4 \%$ used non-caffeinated prescription stimulant medications, $15.9 \%$ used illicit drugs, $69.2 \%$ used stimulants for enjoyment, $39.7 \%$ used stimulants to stay awake, and $29.8 \%$ used stimulants to improve their physical or mental performance.

EMS personnel have been shown to have high rates of depression, post-traumatic stress disorder and sleep disturbances, all of which have been associated with substance abuse. ${ }^{[27,31]}$ Similar to a study that investigated substance use among 206 healthcare workers in 15 health facilities in Kenya, where rates of consumption of illicit stimulants were $9.3 \%$ for marijuana and sedatives together, $8.8 \%$ for cocaine, $6.4 \%$ for amphetamine-like stimulants and $5.4 \%$ for hallucinogens, ${ }^{[25]}$ in our study, marijuana was consumed by $13.7 \%$ of respondents, cocaine by $2.5 \%$ and methamphetamines and amphetamines by $1 \%$. In contrast, none of the respondents in the Nigerian study ${ }^{[24]}$ used illicit drugs. The authors of that study attributed this positive finding to local cultural stigmatisation. ${ }^{[24]}$

Table 2. Reasons for stimulant consumption and increasing frequency of stimulant consumption $(N=315)$

\begin{tabular}{ll} 
Table 2. Reasons for stimulant consumption and increasing frequency of stimulant consumption $(\mathbf{N = 3 1 5})$ & $\boldsymbol{n}(\mathbf{\%})$ \\
\hline & \\
\hline Reasons for stimulant consumption & $218(69.2)$ \\
Enjoyment & $125(39.7)$ \\
To stay awake/alert & $94(29.8)$ \\
To improve physical or mental performance & $52(16.5)$ \\
Cannot function without it & $25(7.9)$ \\
Not sure why & $14(4.4)$ \\
Because everyone does it & $111(35.2)$ \\
Increased frequency of stimulant consumption over time & \\
Reasons for increased frequency of stimulant consumption $(N=111)$ & $85(76.6)$ \\
To combat stress & $54(48.6)$ \\
When the intensity of my work is increased & $51(45.9)$ \\
To stay awake or alert & $31(27.9)$ \\
My shifts are too long & $29(26.1)$ \\
I work too many shifts & $13(11.7)$ \\
There is no trigger for my increased consumption &
\end{tabular}


Prescription stimulant medications such as methylphenidate and modafinil are frequently used by healthcare personnel to improve concentration, memory, wakefulness, motivation, energy, performance and mood. ${ }^{[12]}$ Compared with a study conducted at a medical centre in the USA, where $>50 \%$ of healthcare workers tested positive on urine drug screening for prescription stimulant medications used to treat attention deficit hyperactivity disorder, ${ }^{[32]}$ only $4.4 \%$ of respondents in this study reported the use of prescription stimulant medications such as methylphenidate and modafinil. The fact that access to methylphenidate in SA is more restricted (schedule 6 drug) ${ }^{[33]}$ than in the USA (schedule 2 drug) ${ }^{[34]}$ is a probable reason for the big difference between the two studies.

As a result of long working hours, high workloads and physical and mental demands, the prevalence of sleep disorders is high among EMS personnel. ${ }^{[16]}$ Physical and mental fatigue has been shown to affect $50 \%$ of EMS personnel in the USA, ${ }^{[18]}$ while excessive daytime sleepiness was experienced by $39.2 \%$ of EMS personnel in a study in Taiwan. ${ }^{[35]}$ In comparison, in the present study, difficulty staying awake during a shift was reported by $73.3 \%$ of respondents and insomnia by $22.5 \%$, while $10.5 \%$ perceived that their insomnia was secondary to stimulant use. Similarly, a study investigating energy drink consumption among medical students and junior doctors in Malta reported that $31.9 \%$ of respondents experienced insomnia after consuming energy drinks. ${ }^{[36]}$

\section{Study limitations}

Limitations of the present study are that it was a regional study conducted in Gauteng, so our findings may not be representative of other regions where work stresses, cultural values and access to various products may differ. Furthermore, other limitations that pertain to questionnaire-based studies in general, including recall bias and selective non-disclosure, are also applicable to this study.

\section{Conclusions}

This study demonstrates that the prevalence of stimulant use among EMS personnel in Gauteng, SA, is a cause for concern. Strategies that may be useful in curbing the excessive use of stimulant products among EMS and other healthcare personnel should be aimed at promoting awareness and education, improving working conditions, enhancing support structures, and regulating the stimulant content of commercial products.

Declaration. The research for this study was done in partial fulfilment of the requirements for L-RvR's MSc (Emergency Medicine) degree at the University of the Witwatersrand.

\section{Acknowledgements. None.}

Author contributions. L-RvR: primary author and was responsible for the study design, data collection, data analysis, interpretation of results, manuscript write-up, revision, and approval of the final manuscript. RG and AEL: assisted with the study design, interpretation of the results, revision of the manuscript and approval of the final manuscript

Funding. None.

Conflicts of interest. None.

\footnotetext{
1. Murray A, Traylor J. Caffeine Toxicity. Treasure Island, Fla.: StatPearls Publishing, 2020.

2. McLellan TM, Caldwell JA, Lieberman HR. A review of caffeine's effects on cognitive, physical and occupational performance. Neurosci Biobehav Rev 2016;71:294-312. https://doi.org/10.1016/j. occupational perform
neubiorev.2016.09.001
}

3. Favrod-Coune T, Broers B. The health effect of psychostimulants: A literature review Pharmaceuticals 2010;3(7):2333-2361. https://doi.org/10.3390/ph3072333

4. Stacey N, van Walbeek C, Maboshe M, Tugendhaft A, Hofman K. Energy drink consumption and marketing in South Africa. Prev Med (Baltim) 2017;105(Suppl):S32-S36. https://doi.org/10.1016/j. ypmed.2017.05.01

5. Alsunni AA. Energy drink consumption: Beneficial and adverse health effects. Int J Health Sci (Qassim) 2015;9(4):459-465. https://doi.org/10.12816/0031237

6. Shearer J, Graham TE. Performance effects and metabolic consequences of caffeine and caffeinated energy drink consumption on glucose disposal. Nutr Rev 2014;72(4):121-136. https://doi.org/10.1111/ nure. 12124

7. Mort JR, Kruse HR. Timing of blood pressure measurement related to caffeine consumption. Ann Pharmacother 2008;42(1):105-110. https://doi.org/10.1345/aph.1k337

8. Worthley MI, Prabhu A, de Sciscio P, Schultz C, Sanders P, Willoughby SR. Detrimental effects of energy drink consumption on platelet and endothelial function. Am J Med 2010;123(2):184-187. https://doi.org/10.1016/j.amjmed.2009.09.013

9. Pinto SC, Bandeca MC, Silva CN, Cavassim R, Borges AH, Sampaio JEC. Erosive potential of energy 9. Pinto SC, Bandeca MC, Silva CN, Cavassim R, Borges AH, Sampaio JEC. Erosive potential of energy
drinks on the dentine surface. BMC Res Notes 2013;6(1):67. https://doi.org/10.1186/1756-0500-6-67

10. Temple JL, Hostler D, Martin-Gill C, et al. Systematic review and meta-analysis of the effects of caffeine in Temple JL, Hostler D, Martin-Gill C, et al. Systematic review and meta-analysis of the effects of caffeine
in shift workers: Implications for emergency medical services personnel. Prehosp Emerg Care in fatigued shift workers: Implications for emergency medical services per
2018;22(Suppl 1):37-46. https://doi.org/10.1080/10903127.2017.1382624

11. Hashem KM, He FJ, MacGregor GA. Cross-sectional surveys of the amount of sugar, energy and caffeine in sugar-sweetened drinks marketed and consumed as energy drinks in the UK between 2015 and 2017: Monitoring reformulation progress. BMJ Open 2017;7(12):e018136. https://doi. org/10.1136/bmjopen-2017-018136

12. Retief $M$, Verster C. Prevalence and correlates of non-medical stimulants and related drug use in a sample of South African undergraduate medical students. S Afr J Psychiatry 2016;22(1):6. https://doi. org/10.4102/sajpsychiatry.v22i1.795

13. Ford JA, Schroeder RD. Academic strain and non-medical use of prescription stimulants among college students. Deviant Behav 2008;30(1):26-53. https://doi.org/10.1080/01639620802049900

14. McLaughlin-Chaisson N, Ward S, Beaulieu K, Curtis B, Johnson M. Fatigue in EMS shift workers. Can Paramed 2013;36(5):26-27.

15. Franke AG, Bagusat C, Dietz P, et al. Use of illicit and prescription drugs for cognitive or mood enhancement among surgeons. BMC Med 2013;11(1):102. https://doi.org/10.1186/1741-7015-11-102

6. Sofianopoulos S, Williams B, Archer F. Paramedics and the effects of shift work on sleep: A literature 6. Sofianopoulos S, Williams B, Archer F. Paramedics and the effects of shift work on
review. Emerg Med J 2012;29(2):152-155. https://doi.org/10.1136/emj.2010.094342

17. Frese M, Greif S. Stress at work. J Organ Behav 1981;2(1):73-75. https://doi.org/10.1002/ job. 4030020107

18. Patterson PD, Weaver MD, Weaver SJ, et al. Measuring teamwork and conflict among emergency medical technician personnel. Prehosp Emerg Care 2012;16(1):98-108. https://doi.org/10.3109/1090 3127.2011 .616260

19. Harris PA, Taylor R, Thielke R, Payne J, Gonzalez N, Conde JC. Research electronic data capture (REDCap) - a metadata-driven methodology and workflow process for providing translational research informatics support. J Biomed Inform 2009;42(2):377-381. https://doi.org/10.1016/j. jbi.2008.08.010

20. Zhao I, Turner C. The impact of shift work on people's daily health habits and adverse health outcomes. Aust J Adv Nurs 2008;25(3):8-22.

21. Bonnell EK, Huggins CE, Huggins CT, McCaffrey TA, Palermo C, Bonham MP. Influences on dietary choices during day versus night shift in shift workers: A mixed methods study. Nutrients 2017;9(3):193. https://doi.org/10.3390/nu9030193

22. Kent G, Mason P, Batt AM. Eat, sleep and be healthy: A paramedic's guide to healthier shift work. Can Paramed 2016;39(2):31-34

23. Jahnke S, Kaipust C. Health \& Wellness: The energy drink issue. Firehouse, 1 October 2017. https:// www.firehouse.com/safety-health/article/12365422/health-wellness-the-energy-drink-issue (accessed 7 November 2020)

24. Adamu H, Ahmad MM, Mudi K, Dakani KM, Bakare AT. Predictors of stimulants use among physicians in a Nigerian tertiary health institution in Sokoto, Northwest Nigeria. J Neurosci Behav Health 2018;10(2):9-17. https://doi.org/10.5897/JNBH2018.0151

25. Mokaya AG, Mutiso V, Musau A, et al. Substance use among a sample of healthcare workers in Kenya: A cross-sectional study. J Psychoactive Drugs 2016;48(4):310-319. https://doi.org/10.1080/02791072. 2016.1211352

26. Giesinger K, Hamilton DF, Erschbamer M, Jost B, Giesinger JM. Black medicine: An observational study of doctors' coffee purchasing patterns at work. BMJ 2015;351:h6446. https://doi.org/10.1136/ bmj.h6446

27. Leka S, Griffiths A, Cox T. Work organisation and stress. Geneva: World Health Organization, 2003. https://www.who.int/occupational_health/publications/pwh3rev.pdf (accessed 23 November 2020).

8. Mountfor S, Sharma S. EMS Provider Health And Wellness. Treasure Island, Fla.: StatPearls Publishing. 2020.

29. European Food Safety Authority (EFSA) Panel on Dietetic Products, Nutrition and Allergies. Scientific opinion on the safety of caffeine. EFSA J 2015;13(5):14102. https://doi.org/10.2903/j.efsa.2015.4102

30. Murphy T, Darracq M, Marshall J, Demers G. Neurocognitive enhancement substances use in emergency medical services personnel. Presented at the National Association of EMS Physicians Annual Meeting, San Diego, Calif., 14 - 16 January 2016. https://www.researchgate.net/ publication/290805187_Neurocognitive_Enhancement_Substances_Use_in_Emergency_Medical_ Services_Personnel (accessed 23 November 2020).

31. Fjeldheim CB, Nöthling J, Pretorius K, et al. Trauma exposure, posttraumatic stress disorder and the effect of explanatory variables in paramedic trainees. BMC Emerg Med 2014;14(1):11. https://doi. org/10.1186/1471-227X-14-11

32. Obafemi A. Drug use pattern among health care workers. J Med Toxicol Clin Forensic Med 2017;3(1):1-4. https://doi.org/10.21767/2471-9641.100024

33. Snyman J. Monthly Index of Medical Specialities (MIMS). Vol. 55. Johannesburg: MIMS, 2015

33. Snyman . Monthly Index of Medical Specialities (MIMS). Vol. 55. Johannesburg: MIMS, 2015.
34. Campus Drug Prevention. Drug scheduling and penalties. https://www.campusdrugprevention.gov/ content/drug-scheduling-and-penalties (accessed 23 November 2020).
cons

35. Lin M-H, Huang Y-C, Chen W-K, Wang J-Y. Sleepiness and injury risk in emergency medical service workers in Taiwan. PLoS ONE 2020;15(2):e0229202. https://doi.org/10.1371/journal.pone.0229202

36. Grech A, Axiak S, Pace L, Fondocaro DV. A survey of energy drinks consumption amongst medical students and foundation year doctors in Malta. Malta Medical School Gazette 2019;3(3):59-66. 